\title{
John Emsley: Molecules of murder. Criminal molecules and classic cases
}

\author{
D. Thorburn Burns
}

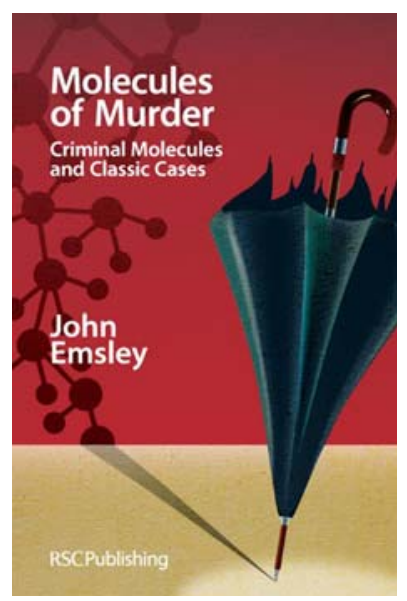

\section{Bibliography}

Molecules of murder. Criminal molecules and classic cases John Emsley RSC Publishing ISBN: 978-0-85404-965-3

Hardcover, 276 pages, August 2008, £14.95

The book's topic Molecules of Murder is about famous murders and famous victims. It analyses crimes from the viewpoint of the poison itself, throwing light on how the murders or attempted murders were carried out and how the perpetrators were discovered and brought to justice.

Content The book commences with a brief account of the milestones in the forensic analysis of poisons. The first main part, "Some of nature's deadly chemicals: from medicine to murder", deals with naturally occurring molecules: ricin, hycoscine, atropine, diamorphine and adrenaline. All except for ricin were used in medical practice before becoming notorious as murder weapons. The second main part, "Dangerous man-made chemicals: so simple, so useful, so deadly", deals with man-made compounds: chloroform, carbon monoxide, cyanide, paraquat and polonium chloride. They too have been misused in famous crimes.

D. T. Burns $(\bowtie)$

The Science Library, The Queen's University of Belfast,

Belfast BT9 5EQ, Northern Ireland

e-mail: profburns@chemistry.fsbusiness.co.uk
The first half of each chapter considers the target compound itself, its history, its chemistry, its use in medicine, its toxicology, and its effect on the human body. The second half deals with a famous murder case involving the specific poison, the modus operandi of the poisoner, and how some-but not all-were caught.

The book concludes with suggestions for further reading, a glossary of chemical terms used in the text, and a comprehensive index.

Comparison with existing literature The nearest comparable book is the author's Elements of Murder. Most current undergraduate texts that deal with the chemical aspects of forensic science deal with the subject technique by technique; they do not develop case studies with the breadth or depth of those included in the book under review here, or put them in context, which the book does too.

Critical assessment This was written as a popular book on an aspect of forensic science. By exploiting the current popular entertainment interest in crime and providing an attractive account of aspects of forensic chemistry, the author aimed to encourage some general appreciation of the roles of pharmaceutical, forensic and research chemists and encourage the young to join in. It also has a wider use as an introduction to the excitement available in the field of analytical chemistry, and it can refresh or revitalize this excitement in older chemistry graduates. The cases outlined also provide much excellent material that can illustrate and enliven many specific technique areas in current undergraduate courses in chemistry.

Summary Molecules of Murder provides an attractive account of some historic murders performed by poisoning, which is carefully researched and documented, and skilfully presented in a manner suitable for the general public as well as for those with a background in chemistry. 